\title{
Development and Calibration of a Dual Drainage Model for the Cooksville Creek Watershed, Canada
}

\author{
Mark Randall, ${ }^{1}$ Nandana Perera, ${ }^{2}$ Neelam Gupta ${ }^{3}$ and Muneef Ahmad \\ ${ }^{1}$ University of Copenhagen, Copenhagen, Denmark; ${ }^{2}$ Computational Hydraulics International, Guelph, Ontario; ${ }^{3}$ Credit Valley Conservation \\ Authority, Mississauga, Ontario; ${ }^{4}$ City of Mississauga, Mississauga, Ontario.
}

\begin{abstract}
Under storm conditions urban stormwater drainage systems may undergo various flow regimes including backwater, surcharging, reverse flow and surface ponding. Evaluation of the performance of a stormwater management system under these different conditions requires detailed hydraulic grade line analysis of both the minor and major drainage systems. Computational Hydraulics International, the Credit Valley Conservation Authority and the City of Mississauga have worked in collaboration to develop a high resolution hydrologic-hydraulic dual drainage model to address these needs for the highly urbanized and flood vulnerable Cooksville Creek watershed. This paper presents the model development, parameterization, calibration and validation. The completed model consists of $>4000$ subcatchments covering the $33 \mathrm{~km}^{2}$ drainage area and $>8000$ conduits representing $>500 \mathrm{~km}$ of drainage network including storm sewer pipes, major system flow paths, ditches and the creek itself. A comparison of observed and computed maximum and total flow volumes at the creek's flow gauge for 12 calibration events yielded Nash-Sutcliffe model efficiency coefficient values of 0.86 and 0.82 respectively.
\end{abstract}

\section{Introduction}

Flooding in urban areas caused by extreme rainfall events can lead to significant property damage and human injury. Aging drainage infrastructure, expanding impervious areas, growing urban populations and the potential for greater rainfall intensities due to climate change can all serve to increase the risks associated with flooding. The use of sophisticated hydrologic and hydraulic models as design and decision support tools has become a standard practice in the field of flood management. However complexities in the urban environment and drainage infrastructure can pose distinct modeling challenges.

Urban stormwater drainage systems can be described in terms of two main components: the minor system and the major system. The minor system consists primarily of subsurface storm sewer pipes and is typically designed to accommodate the runoff from more frequent events (e.g. $5 \mathrm{y}$ to $10 \mathrm{y}$ return period storms). The major system includes streets, and various natural and artificial channels, and is typically designed to accommodate flows in excess of what can be carried in the minor system during very large events (e.g. $50 \mathrm{y}$ to $100 \mathrm{y}$ return period storms). These two systems are linked at curb inlets which allow runoff into (and in some cases out of) the storm sewer system. Over the past several decades there has been an effort in the field of urban drainage modeling to better represent the linkage between major and minor systems and simulate storm sewer overflow and street flooding in a realistic manner. A dual drainage model is one that "takes into account not only the flow through the sewer system, but also the flow on the surface" (Djordjević et al. 1999).

Smith (2006) provides a detailed history of dual drainage modeling beginning with perhaps its earliest mention in the design manuals of the City of Denver, Colorado (Denver Regional Council of Governments 1969). In his discussion paper Smith details the contributions of numerous researchers over the decades to address the challenges encountered. Wisner and Kassem (1982) suggested that the models at that time were not suitable for dual drainage as they assumed that all runoff is routed directly into the minor system. Djordjević et al. (1991) showed that the flows in the storm sewers are very dependent on whether excess volumes are allowed to flow along the street or stored in a fictitious basin above the surcharging manhole. Djordjević et al. (1999) identified weak points of the day's models as being "coarse surface descriptions" and a "lack of interaction between surface and underground flow components."

Many of today's stormwater models are better able to address the challenges encountered in the earlier years of dual drainage modeling. The Stormwater Management Model (SWMM5, Rossman 2015), for example, takes into account the channel storage, pressurized flow, backwater, surcharging, reverse flow and surface ponding conditions required to simulate the interactions between major and minor systems. Furthermore, the increasing quality and availability of GIS data combined with swiftly advancing GIS tools to aid with the rapid delineation and parameterization of numerous drainage areas allows for increasingly

Randall, Mark, Nandana Perera, Neelam Gupta and Muneef Ahmad. 2017. Development and Calibration of a Dual Drainage Model for the Cooksville Creek Watershed, Canada. Journal of Water Management Modeling 25:C419.

https://doi.org/10.14796/JWMM.C419 @ CHI 2017. www.chijournal.org ISSN 2292-6062. 
representative land surface descriptions. Mark et al. (2004) stated that "a combination of GIS and 1D hydrodynamic modeling constitutes a cost efficient system for planning and management of drainage systems suffering from urban flooding." Integrating a 2D (two dimensional) component can allow for a better representation of overland flow paths in a dual drainage model (Leandro et al. 2009), but for long term modeling of city wide drainage systems the computational costs of this approach remain high.

Real world examples of dual drainage modeling are now needed to serve as case studies demonstrating the input requirements, capabilities and limitations of these techniques for use in a variety of urban settings. This paper presents the dual drainage model created in response to recent flooding in the Cooksville Creek watershed in Southern Ontario. The focus of this paper will be on the data inputs, setup, parameterization, calibration and validation of the model. Ongoing model uses, recommendations to improve the model's accuracy and suggestions for further analysis are also discussed.

\section{Study Area}

Cooksville Creek is a highly urbanized watershed approximately $30 \mathrm{~km}$ west of downtown Toronto, Ontario. Land use within the $33 \mathrm{~km}^{2}$ subcatchment is approximately $60 \%$ residential and $34 \%$ commercial and industrial, and very limited natural cover still exists along the creek. The elevation of the watershed varies from $190 \mathrm{~m}$ amsl (above mean sea level) in the upstream areas to $75 \mathrm{~m}$ amsl at the outlet to Lake Ontario. Impervious cover is approximately $48 \%$, and soil in the area has been characterized as having low hydraulic conductivity. Cooksville Creek is $\sim 18 \mathrm{~km}$ long with a flashy hydrologic response due to the highly urbanized nature of the watershed. Much of Mississauga (population 700 000) lies within the Cooksville Creek watershed (see map in Figure 1).

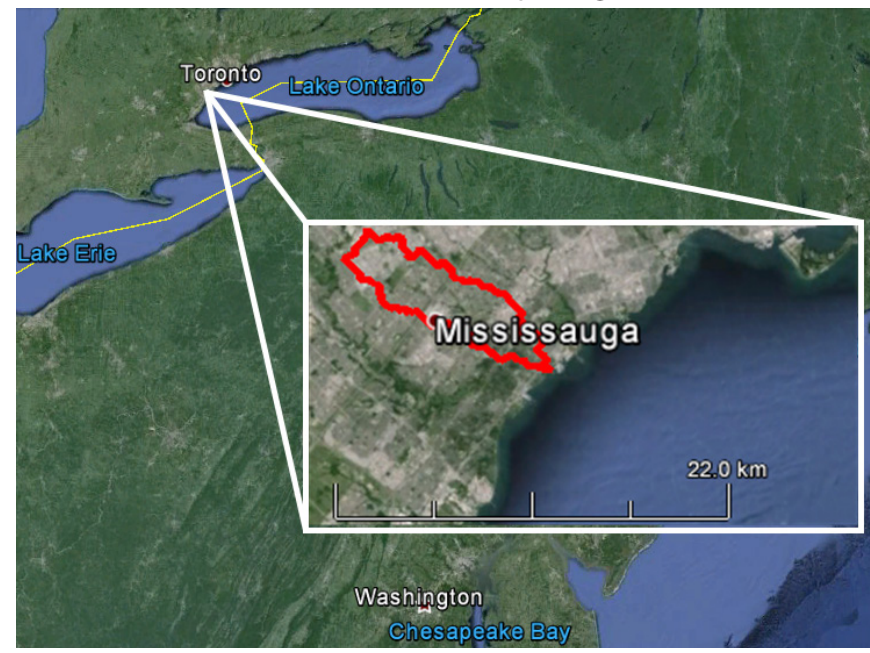

Figure 1 Cooksville Creek watershed (image from Google Earth, 2016).

The Cooksville Creek watershed experienced several major storm events in recent years which caused significant damage to public and private property and infrastructure. The events of 2009-08-04 and 2013-07-08 had $68 \mathrm{~mm}$ and $80 \mathrm{~mm}$ of rainfall respectively and both occurred within $<3 \mathrm{~h}$. These recent flooding events have drawn attention to the need for a detailed evaluation of both the major and minor drainage systems.

The minor drainage system in the watershed consists mainly of circular concrete pipes with large rectangular conduits and grassed ditches in some areas. The major drainage system consists of mostly asphalt covered roads. Current practice in Mississauga is to design minor and major drainage system components for $10 \mathrm{y}$ and $100 \mathrm{y}$ design storms respectively.

\section{Model Development}

\subsection{Software}

All model development and calibration was performed in PCSWMM, a GIS based spatial decision support system that provides an engineering planning, design, and management environment for the official version of the SWMM5 engine developed by the United States Environmental Protection Agency (USEPA). SWMM5 is a dynamic rainfall-runoff-routing simulation model used for single event and long term simulation of water quantity and quality (Rossman 2015).

\subsection{Model Overview}

The dual drainage model includes subcatchments, major and minor system components, stormwater outfalls and the creek itself. An existing subcatchment layer with a discretization of the watershed into 120 subcatchments based on topography was considered too coarse to allow for the estimation of flow and hydraulic grade lines in individual pipes. Each of the original subcatchments was further discretized by generating a separate Thiessen polygon for each manhole location and stream junction, resulting in $>4000$ subcatchments ranging in area from 0.02 ha to 16 ha (Figure 2). This approach was taken rather than delineating drainage areas for each manhole based on topography because of the much larger data and time requirement of the latter approach.

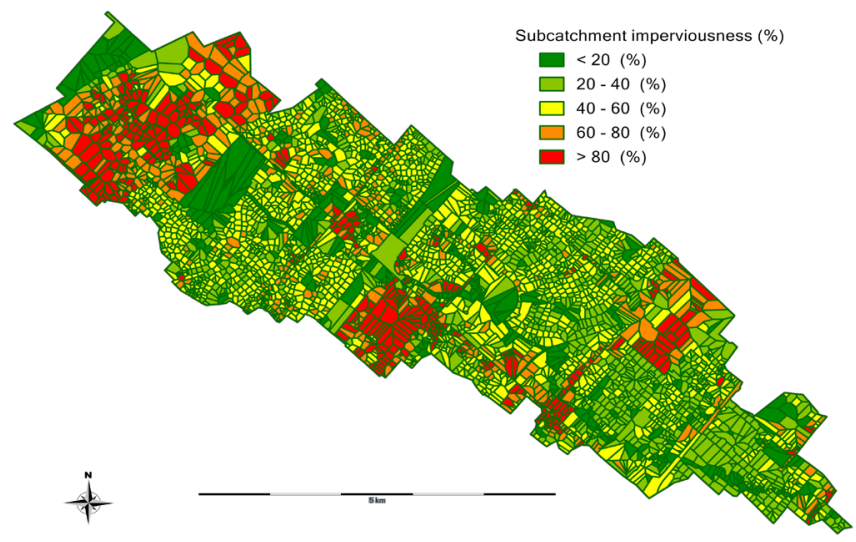

Figure 2 Cooksville Creek watershed subcatchments delineated using a Thiessen polygon approach. 
Hydraulic components were imported into the model from existing HEC-RAS models using PCSWMM import routines as described by James et al. (2012). Coordinates, diameters, materials, slopes and lengths for minor system pipes were imported from GIS data provided by the City of Mississauga. Minor system junctions were imported from a GIS points layer containing manhole locations. Figure 3 shows a map of the model's hydraulic components. An inventory of all SWMM5 entities used to model the Cooksville Creek watershed is presented in Table 1.

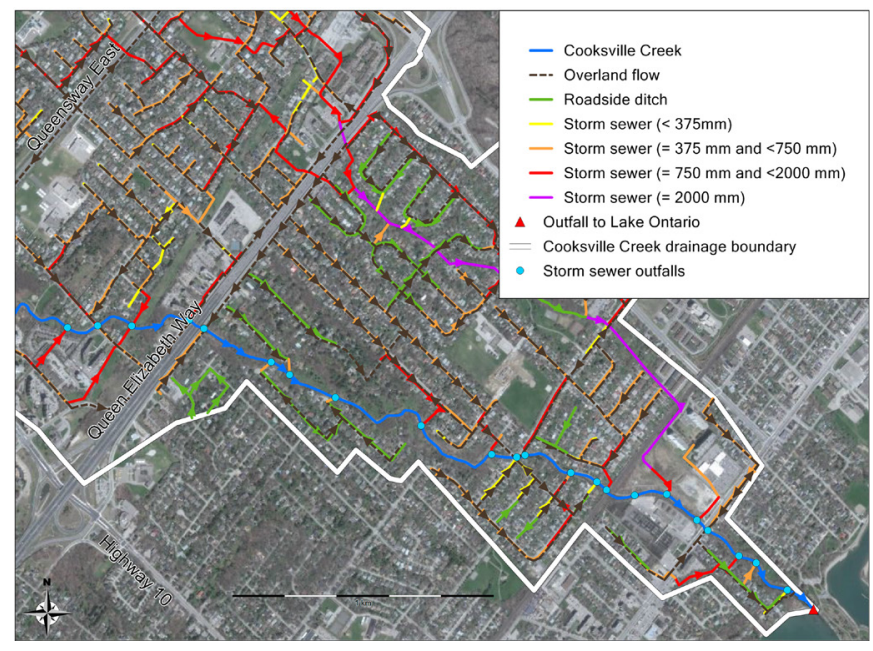

Figure 3 Hydraulic components included in dual drainage model.

Table 1 Inventory of SWWM5 entities in the Cooksville Creek dual drainage model.

\begin{tabular}{lcl}
\hline \multicolumn{1}{c}{ SWWM5 Entity } & Number & \multicolumn{1}{c}{ Description } \\
\hline Minor junctions & 4124 & manholes/catchbasins \\
Major junctions & 3359 & junctions of major system flow paths \\
Minor conduits & 4197 & stormwater pipes and ditches \\
Major conduits & 3540 & overland flow paths \\
Creek conduits & 336 & Cooksville Creek channel \\
Subcatchments & 4385 & Thiessen polygon drainage areas \\
Outfalls & 1 & flow to Lake Ontario \\
Weirs & 85 & link major system conduits to adjacent ditches or creek \\
Outlets & 3268 & link from minor to major system at catchbasin locations \\
Rating curves & 17 & flow restriction of catchbasin grates \\
Transects & 747 & channel geometry \\
Shape curves & 136 & bridge geometry \\
\hline
\end{tabular}

Major system conduits representing street flow were generated parallel to all minor system conduits using PCSWMM's dual drainage creator tool. Along major streets which had no minor system conduits, major system conduits were added manually. Each major system conduit was assigned an irregular transect based on the street width value available in the GIS data. All street cross sections were assumed to have a cross-slope of $0.005 \mathrm{~m} / \mathrm{m}$ and a maximum curb height of $0.23 \mathrm{~m}$. An example of one of the transects assigned to a major system conduit representing a $16 \mathrm{~m}$ wide road is shown in Figure 4.

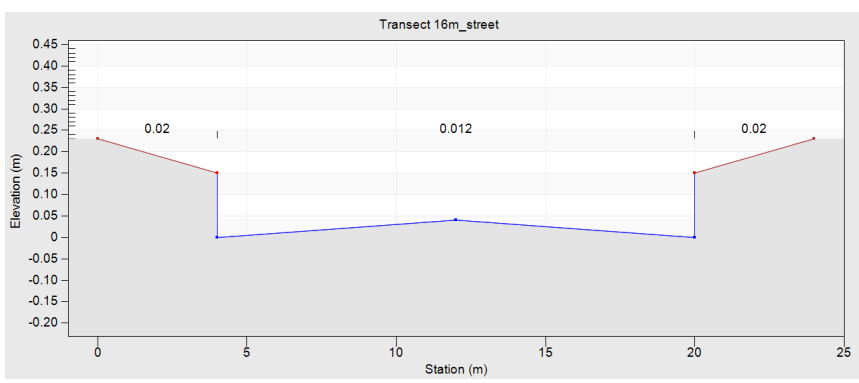

Figure 4 Irregular transect assigned to major system conduit.

\subsection{Model Parameterization}

Subcatchment width in SWMM5 is defined as subcatchment area divided by the average maximum overland flow path length. The initial (i.e. before calibration) flow length was estimated to be $30 \mathrm{~m}$ for all subcatchments based on the average sheet flow length in a typical urban area. The average slope for each subcatchment was calculated using a digital elevation model (DEM) with a grid resolution of $5 \mathrm{~m}$. Slope at each DEM grid cell was calculated in ArcGIS and then average slope for each subcatchment polygon was estimated using the zonal statistics tool.

Subcatchment and conduit parameter values were based on the Appendix Reference Tables in the User's Guide to SWMM (James et al. 2010). Manning's roughness values of 0.011 and 0.240 were assigned to impervious and pervious areas respectively (McCuen et al. 1996). Depression storage values of $2 \mathrm{~mm}$ and $5 \mathrm{~mm}$ were assigned to impervious and pervious areas respectively (ASCE 1992). A GIS layer of impervious areas was generated by combining a buildings layer with a layer outlining sidewalks, roads and parking lots. The average imperviousness of each subcatchment was calculated using the impervious areas polygon layer. In the available soils GIS layer, soil classes were assigned initial parameters based on the average values published by Rawls et al. (1983). Area weighted averaging was used to assign Green-Ampt soil parameters to each subcatchment.

Invert elevation and cross section data for the grassed ditches located in the older residential areas were obtained from the DEM and supplemented with field measurements as necessary. Minor system conduits representing pipes and grassed ditches were assigned Manning's roughness coefficients of 0.013 and 0.030 , respectively. A Manning's roughness of 0.015 was assigned to all major system conduits, representing asphalt cover. Missing or clearly unrealistic pipe invert elevations were linearly interpolated from upstream and downstream pipe elevations where data in the GIS layers was unavailable.

Manhole invert elevations not included in the GIS data were assumed to be equal to the lowest connected pipe invert 
elevation at each junction. Estimates of manhole rim elevations were extracted from the DEM. To prevent loss of water from the model, the major drainage system junctions were assigned a pre-calibration ponded area of $400 \mathrm{~m}^{2}$. This ponded area allows water to accumulate at the junctions until there is capacity available in connected conduits. Junctions within the regulatory flood plain polygon were not assigned a ponded area to avoid duplication of storage around these junctions which is already accounted for by stream cross sections. Minor and major system junctions within these areas were assigned a $5 \mathrm{~m}$ surcharge depth to accommodate increased water depth during flooding.

At each manhole location a SWMM outlet link was used to control flow from the major system to the minor system. Flow through each outlet link was defined by the rating curve for a $600 \mathrm{~mm} \times 600 \mathrm{~mm}$ DD-713B herringbone grate (City of Toronto 2010) multiplied by the number of catchbasins within the subcatchment.

In areas where ditches were present, weir links were used to allow flow between the major system and ditch. At bridge crossings weir links were added to allow major system overflow to enter directly into the creek if water level reached the curb height of $0.23 \mathrm{~m}$. Water surface elevation at the model outfall is taken from a time series of observed daily water levels at the Water Survey of Canada's Toronto Lake Ontario gauge, ID 02HC048 (Environment Canada 2013).

\section{Model Calibration and Validation}

\subsection{Precipitation and Flow Data}

Precipitation time series were available from three rain gauges: S-01 located near the outlet of the watershed; S-06 located in the middle of the watershed; and S-10 located near the top of the watershed. For model calibration, rain gauges were assigned to subcatchments based on proximity as shown in Figure 5.

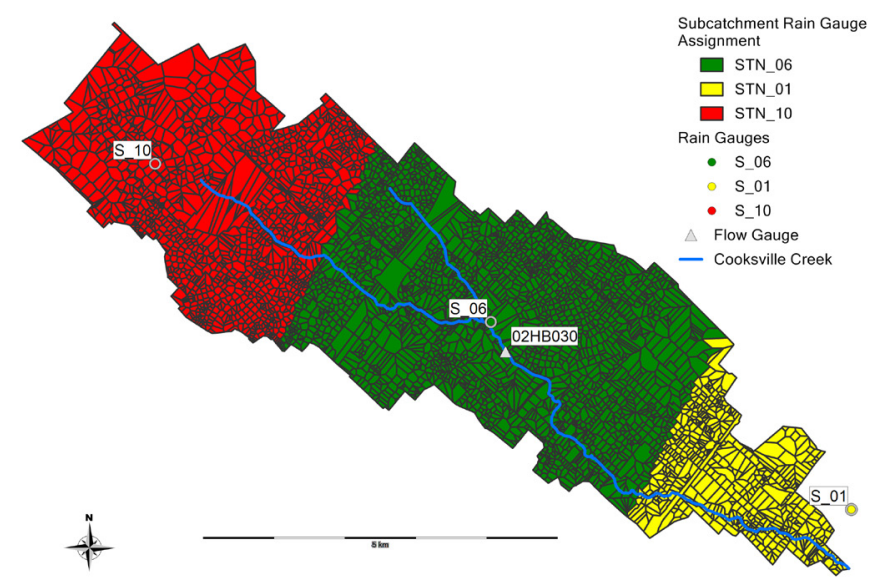

Figure 5 Rain and flow gauge locations.
The flow time series observed at flow gauge 02HB030, located approximately $500 \mathrm{~m}$ downstream of the confluence of the creek's two major tributaries was used for model calibration (see Figure 5). The hydrologic component of the Cooksville Creek model does not include aquifers, as groundwater was not believed to significantly influence drainage. However, a baseline flow of $0.3 \mathrm{~m}^{3} / \mathrm{s}$ was added at the confluence of the two major creek tributaries to represent the constant baseflow observed in the $02 \mathrm{HB} 030$ gauge time series.

\subsection{Calibration Events}

Twelve of the largest events during the snow free period of the years 2009 and 2013 were used for model calibration. Selected event periods were assumed to begin $3 \mathrm{~h}$ before the rainfall started and end $6 \mathrm{~h}$ after rainfall ended (based on a threshold rainfall intensity of $10 \mathrm{~mm} / \mathrm{h}$ ). Total precipitation and maximum 5 min intensity for selected calibration events are shown in Table 2. The System rainfall refers to the average catchment-wide rainfall (i.e. the combined area weighted average for gauges S-01, S-06 and S-10).

Table 2 Calibration event rainfall.

\begin{tabular}{lccccccccc}
\hline \multirow{2}{*}{ Event Date } & Duration & \multicolumn{3}{c}{ Total Rainfall $(\mathrm{mm})$} & \multicolumn{5}{c}{ Maximum Intensity (mm/h) } \\
& (h) & S-01 & S-06 & S-10 & System & S-01 & S-06 & S-10 & System \\
\hline 11-Jul-09 & 10 & 15 & 16 & 14 & 15 & 98 & 120 & 74 & 81 \\
23-Jul-09 & 26 & 22 & 24 & 25 & 24 & 22 & 43 & 26 & 22 \\
25-Jul-09 & 13 & 29 & 27 & 18 & 24 & 50 & 43 & 31 & 23 \\
26-Jul-09 & 16 & 29 & 23 & 13 & 20 & 67 & 74 & 29 & 43 \\
4-Aug-09 & 11 & 19 & 68 & 45 & 53 & 62 & 142 & 134 & 99 \\
9-Aug-09 & 11 & 22 & 19 & 17 & 19 & 77 & 55 & 74 & 55 \\
9-Aug-09 & 12 & 26 & 23 & 28 & 25 & 67 & 53 & 82 & 48 \\
10-Jun-13 & 30 & 33 & 27 & 20 & 25 & 29 & 17 & 24 & 10 \\
16-Jun-13 & 16 & 1 & 13 & 11 & 11 & 2 & 19 & 19 & 11 \\
28-Jun-13 & 12 & 4 & 20 & 7 & 13 & 5 & 70 & 22 & 35 \\
5-Jul-13 & 20 & 15 & 43 & 28 & 34 & 29 & 98 & 48 & 55 \\
8-Jul-13 & 12 & 81 & 71 & 57 & 67 & 221 & 166 & 122 & 126 \\
\hline
\end{tabular}

\subsection{Calibration Parameters}

Using PCSWMM's sensitivity based calibration tools, the original subcatchment and junction parameters were adjusted one at a time within assigned uncertainties to determine the values producing computed flow results in closest agreement with the observed data. The parameters varied for the model calibration runs included: ponded area at junctions, subcatchment width, slope, percent impervious area, pervious area depression storage and roughness, and Green and Ampt infiltration parameters (soil capillary suction head, hydraulic conductivity and initial soil moisture deficit). Table 3 summarizes the initial value ranges and the resulting calibration parameter values as a percent of initial values. 
Table 3 Calibration parameters.

\begin{tabular}{lcc}
\hline \multicolumn{1}{c}{ Calibration Parameter } & Initial Value Range & $\begin{array}{c}\text { Calibrated Values } \\
\text { (\% of Initial) }\end{array}$ \\
\hline Ponded Area $\left(\mathrm{m}^{2}\right)$ & 400 & 50 \\
Subcatchment Width (m) & $0-30$ & 100 \\
& $30-100$ & 87 \\
& $100-300$ & 63 \\
& $300-500$ & 53 \\
& $500-700$ & 45 \\
Slope (\%) & $700-5500$ & 40 \\
Percent Impervious (\%) & $0-7$ & 95 \\
N Perv & $1.5-95$ & 98 \\
Dstore Perv (mm) & 0.24 & 126 \\
Suction Head (mm) & 5 & 123 \\
Conductivity (mm/h) & $110-320$ & 250 \\
Initial Deficit (frac.) & $0.254-10.9$ & 250 \\
\hline
\end{tabular}

\subsection{Validation Events}

For validation of the Cooksville Creek dual drainage model, 12 events occurring during the snow free periods of 2009, 2010 and 2013 were selected. Data from all three rain gauges was not available for 8 of the 12 events so data from the nearest available rain gauge was used to fill in the missing data. Validation event rainfall is summarized in Table 4.

Table 4 Validation event rainfall.

\begin{tabular}{lccccccccc}
\hline \multirow{2}{*}{ Event Date } & Duration & \multicolumn{3}{c}{ Total Rainfall (mm) } & \multicolumn{5}{c}{ Maximum Intensity (mm/h) } \\
& (h) & S-01 & S-06 & S-10 & System & S-01 & S-06 & S-10 & System \\
\hline 20-Aug-09 & 10 & 12 & 39 & 23 & 30 & 118 & 118 & 103 & 97 \\
28-Aug-09 & 17 & NA* $^{*}$ & 35 & 18 & 24 & $\mathrm{NA}^{*}$ & 22 & 14 & 12 \\
26-Sep-09 & 19 & $\mathrm{NA}^{*}$ & 14 & 10 & 12 & $\mathrm{NA}^{*}$ & 10 & 12 & 9 \\
28-Sep-09 & 12 & $\mathrm{NA}^{*}$ & 11 & 13 & 12 & $\mathrm{NA}^{*}$ & 12 & 17 & 11 \\
08-0ct-09 & 31 & 19 & $\mathrm{NA}^{*}$ & 12 & 17 & 5 & $\mathrm{NA}^{*}$ & 7 & 4 \\
23-0ct-09 & 20 & 16 & $\mathrm{NA}^{*}$ & 11 & 14 & 12 & $\mathrm{NA}^{*}$ & 10 & 11 \\
02-Jun-10 & 19 & 27 & $\mathrm{NA}^{*}$ & 29 & 29 & 38 & $\mathrm{NA}^{*}$ & 26 & 23 \\
05-Jun-10 & 18 & 24 & $\mathrm{NA}^{*}$ & 25 & 25 & 12 & $\mathrm{NA}^{*}$ & 10 & 10 \\
16-Jun-10 & 17 & 12 & $\mathrm{NA}^{*}$ & 12 & 12 & 38 & $\mathrm{NA}^{*}$ & 14 & 13 \\
08-Apr-13 & 15 & 11 & 12 & 11 & 12 & 22 & 22 & 12 & 12 \\
09-Apr-13 & 18 & 26 & 20 & 21 & 21 & 10 & 7 & 10 & 8 \\
28-Apr-13 & 17 & 13 & 10 & 11 & 11 & 5 & 5 & 5 & 5 \\
\hline
\end{tabular}

*Data not available (NA).

\section{Calibration Results}

Computed and observed peak and total flows at the flow gauge for the 12 calibration events are shown in Figures 6 and 7 below respectively.

The Nash-Sutcliffe model efficiency coefficient (NSE), a measure of model accuracy, was used to evaluate the performance of the calibration. An NSE of 1 corresponds to a perfect match of computed results to observed data. For the twelve events the calibrated dual drainage model has NSE values of 0.86 and 0.82 for maximum and total event flows respectively, indicat- ing a very good performance at the flow gauge location according to guidelines suggested by Moriasi et al. (2007).

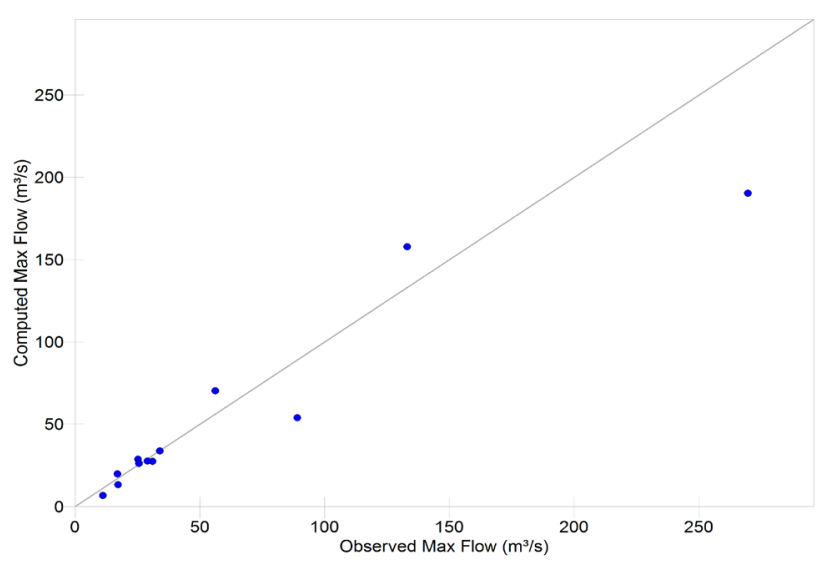

Figure 6 Computed and observed maximum flows of calibration events at $02 \mathrm{HB} 030$ flow gauge.

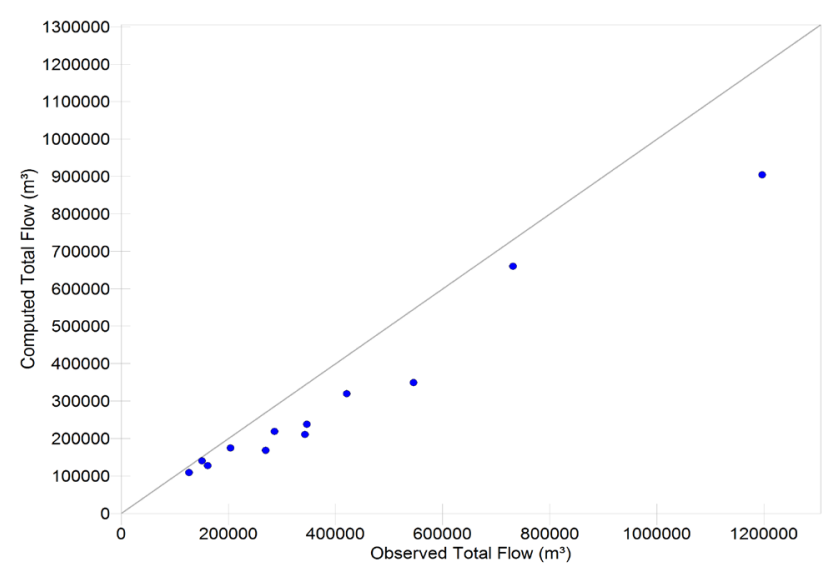

Figure 7 Calibration event computed and observed total flows at the $02 \mathrm{HB} 030$ flow gauge.

Computed peak flow values were divided on either side of the $45^{\circ}$ line. The peak flow of the largest selected calibration event (2013-07-08) was nearly $270 \mathrm{~m}^{3} / \mathrm{s}$ and all other events ranged between $10 \mathrm{~m}^{3} / \mathrm{s}$ and $135 \mathrm{~m}^{3} / \mathrm{s}$. The event with the largest disagreement between computed and observed values was the 2013-07-08 event, which had a computed peak flow approximately $29 \%$ less than the observed peak flow. It is noted that some observed high flows (for example on 2013-07-08) are based on an extrapolated rating curve and therefore may not be as accurate. In terms of total flow volume the computed value for the largest event was $\sim 25 \%$ less than the observed value.

Computed and observed hydrographs for individual calibration events are presented in Figures $8 \mathrm{a}$ to 8 l. Computed hydrograph shapes generally agreed with the observed hydrographs but often had slightly steeper recession limbs. This is likely due partially to the fact that the model does not account for the interflow and groundwater slow response. Spatial variability in rainfall intensity may also have contributed to the differences in the hydrograph shapes. 


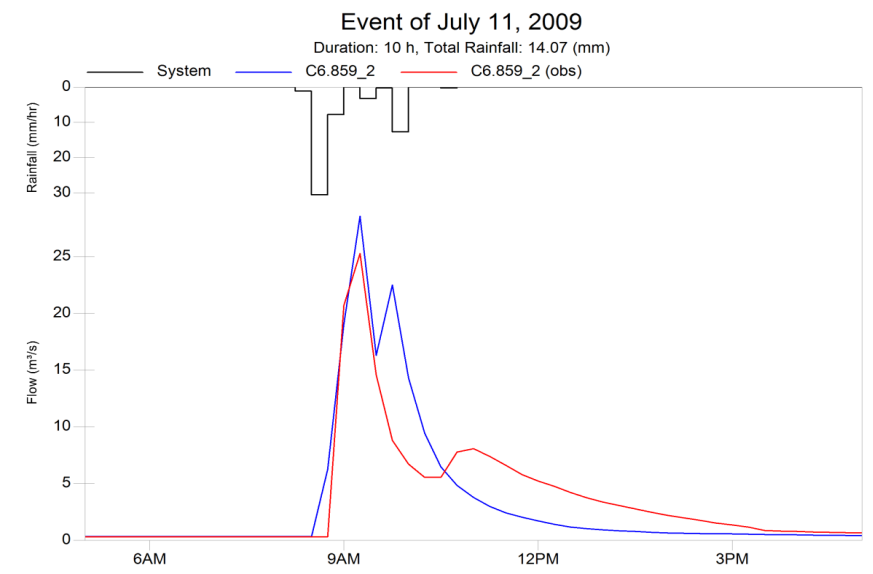

Figure 8a Calibration hydrograph for 2009-07-11 event.

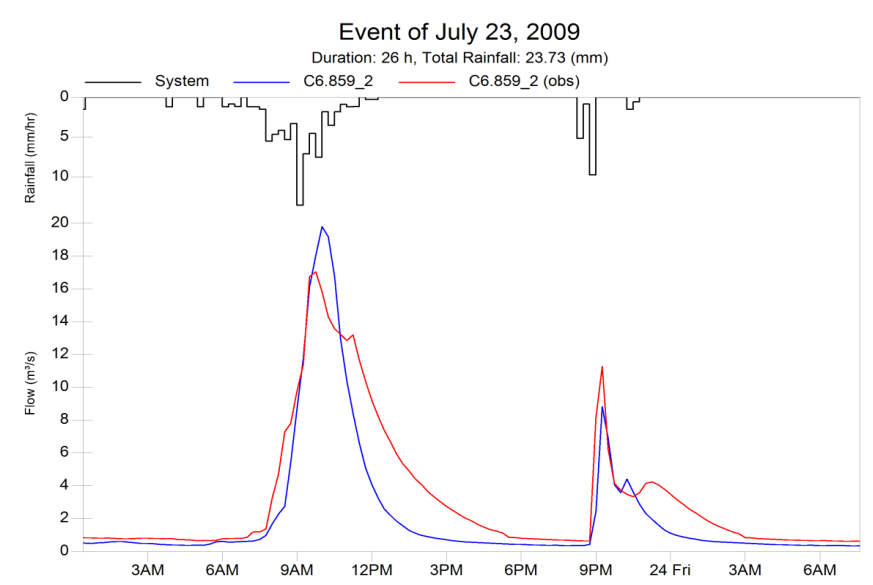

Figure 8b Calibration hydrograph for 2009-07-23 event.

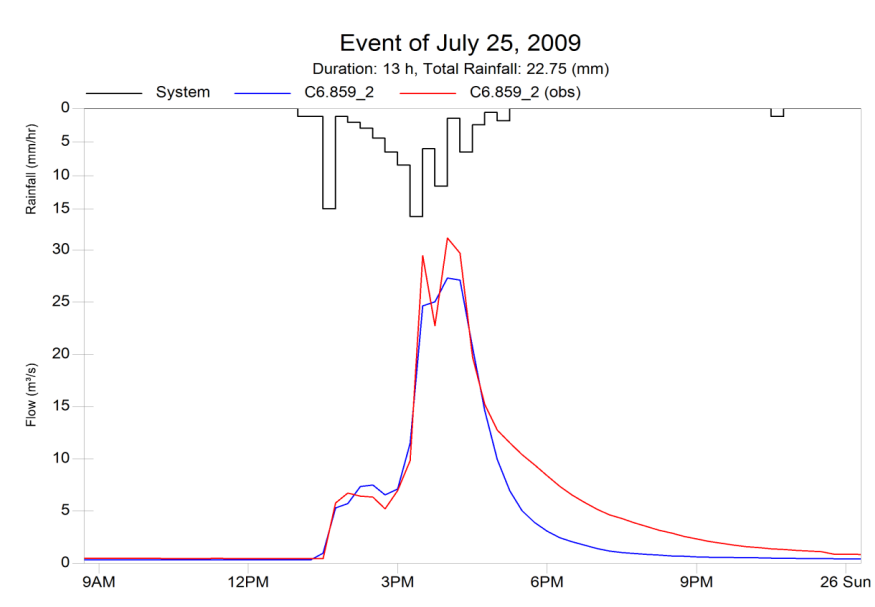

Figure 8c Calibration hydrograph for 2009-07-25 event.

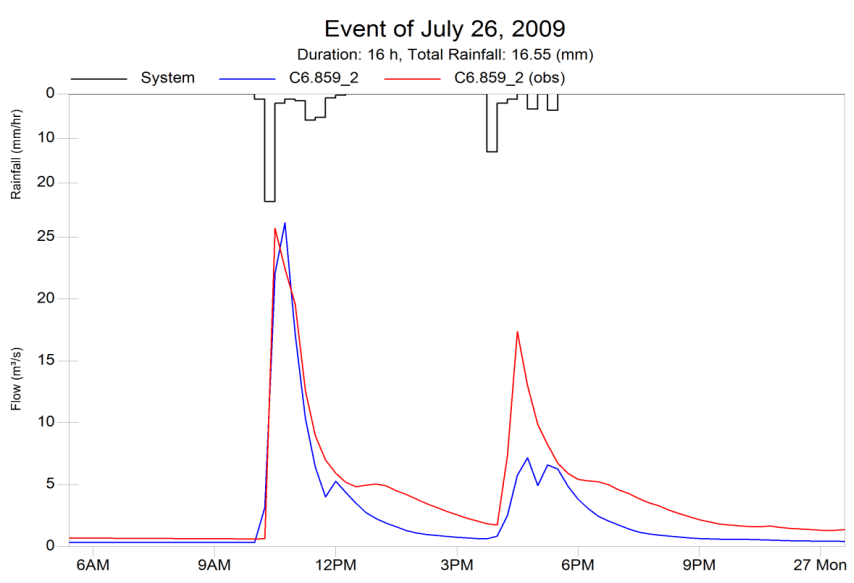

Figure 8d Calibration hydrograph for 2009-07-26 event.

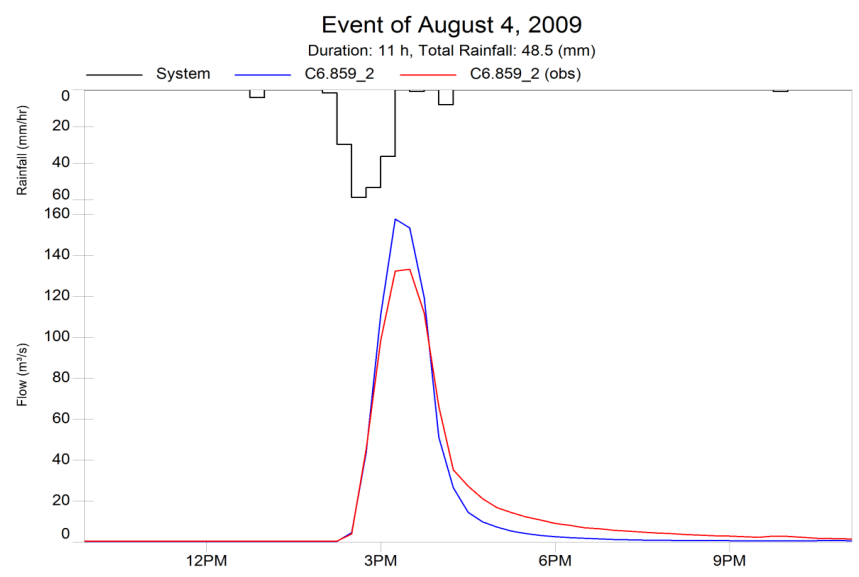

Figure 8e Calibration hydrograph for 2009-08-04 event.

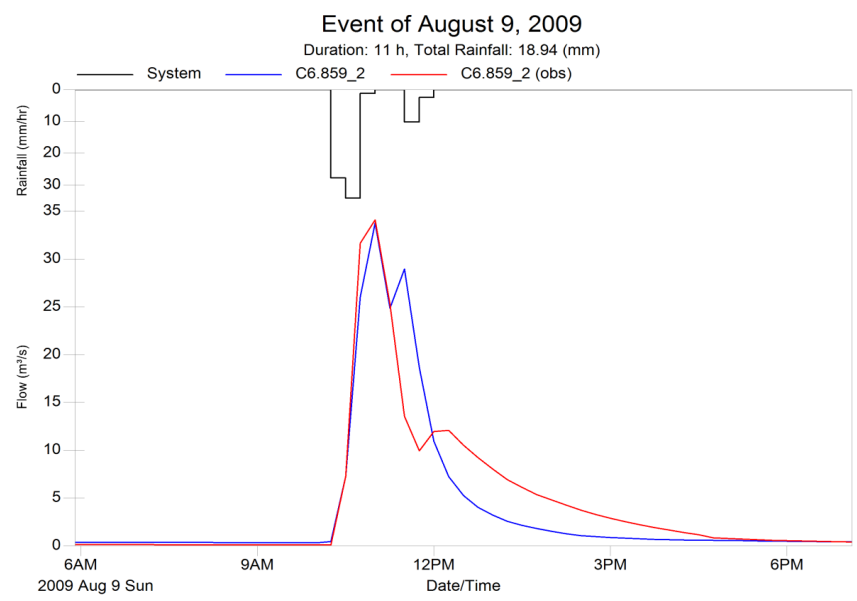

Figure 8f Calibration hydrograph for 2009-08-09 event. 


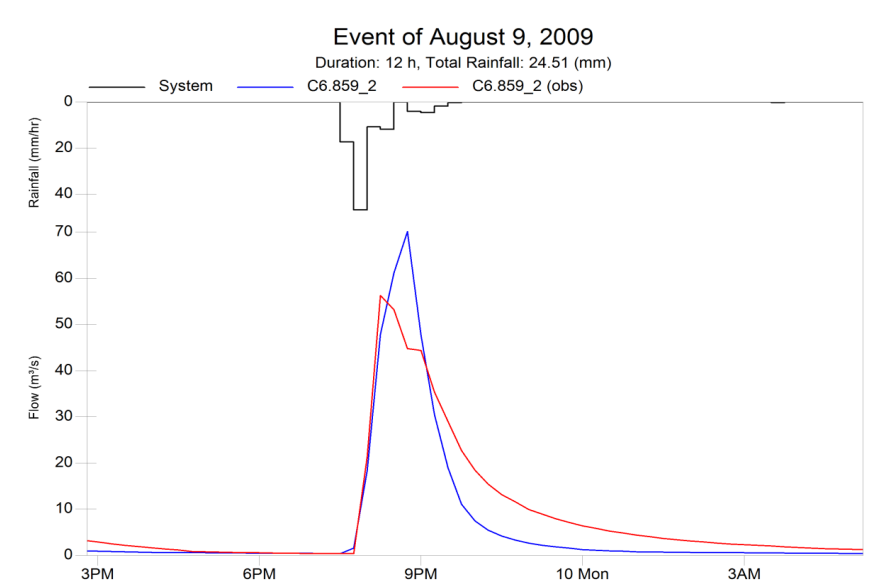

Figure 8g Calibration hydrograph for 2009-08-09 event.

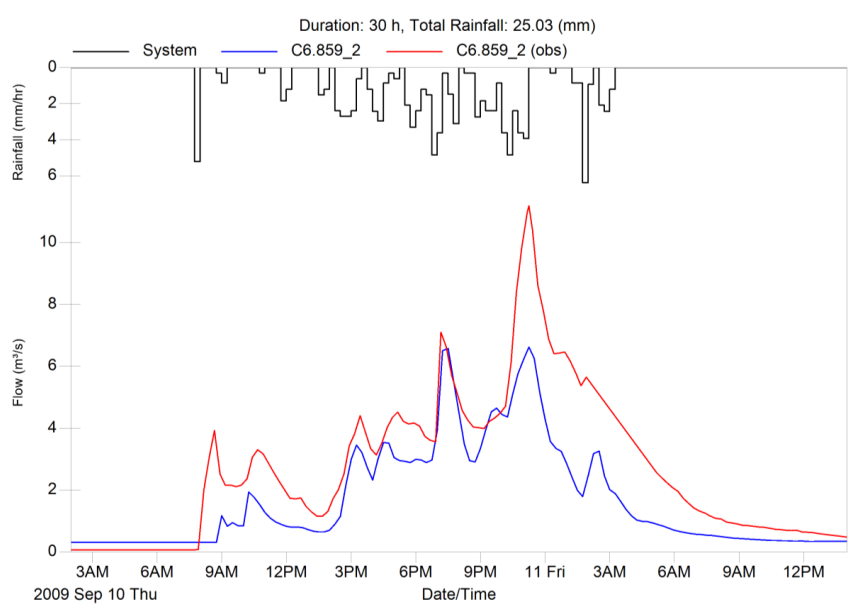

Figure 8h Calibration hydrograph for 2013-06-10 event.

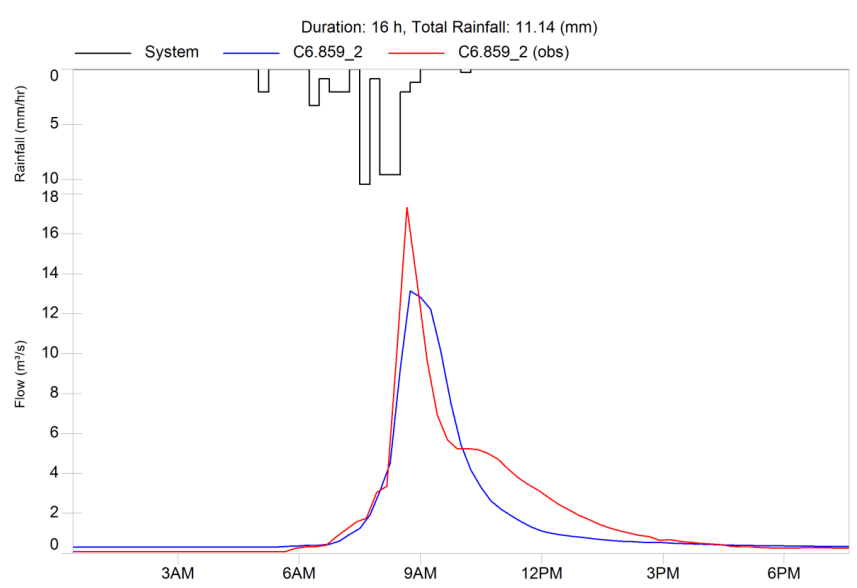

Figure 8i Calibration hydrograph for 2013-06-16 event.

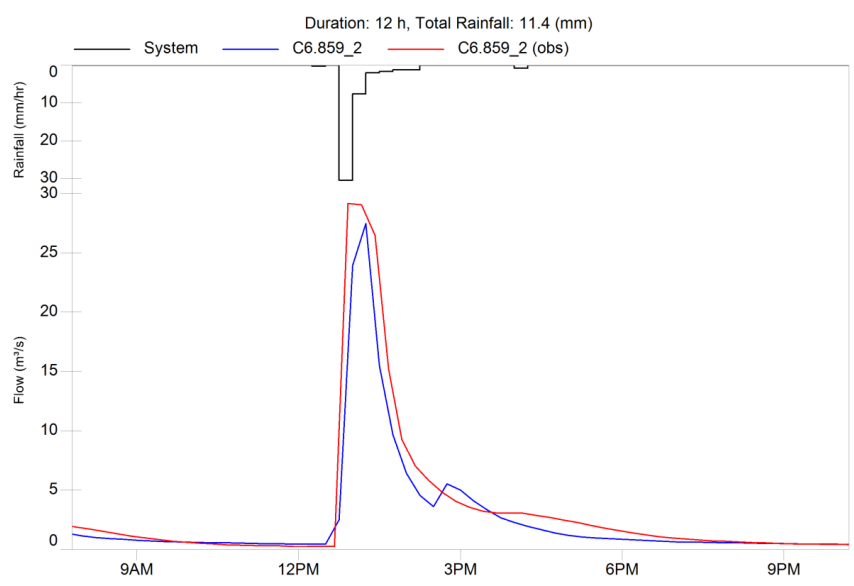

Figure 8j Calibration hydrograph for 2013-06-28 event.

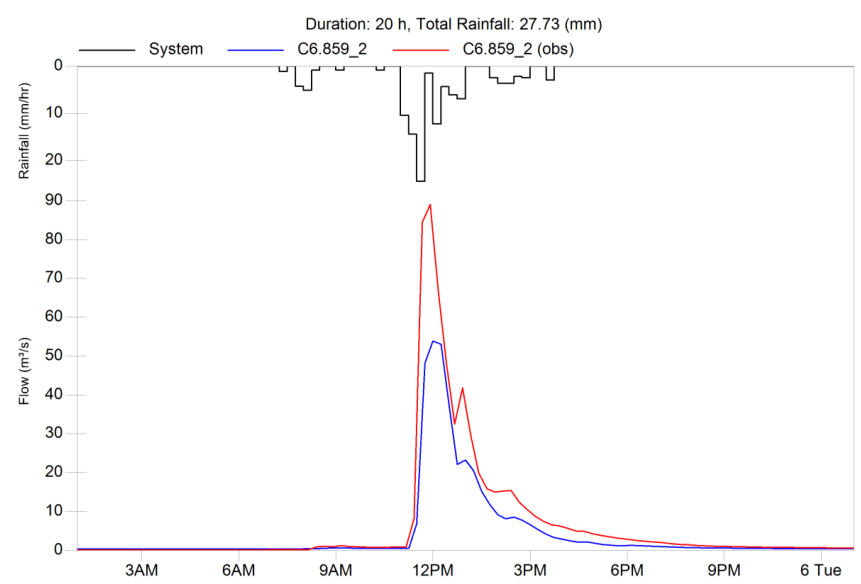

Figure 8k Calibration hydrograph for 2013-07-05 event.

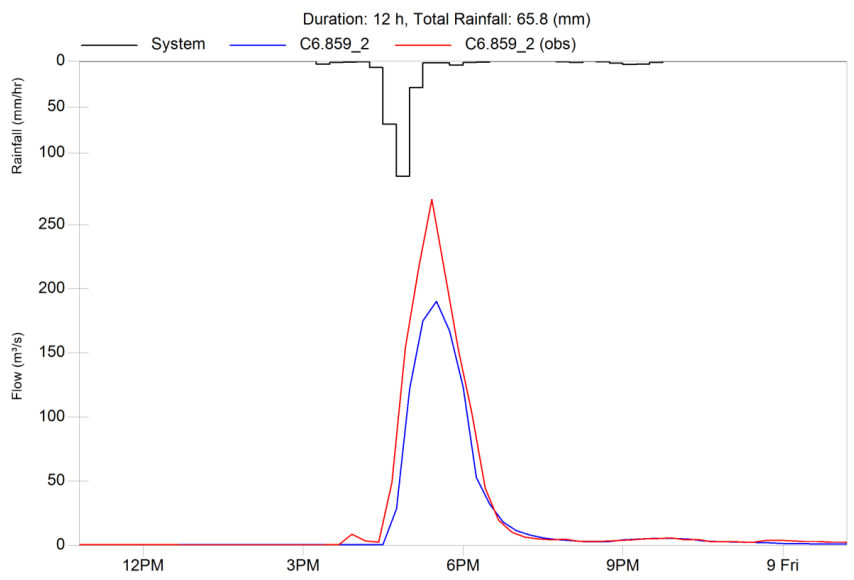

Figure 81 Calibration hydrograph for 2013-07-08 event. 


\section{Validation Results}

Maximum and total flow results of the calibrated model compared to observations for the validation events are presented in Figures 9 and 10 respectively. The NSE values for validation events were 0.91 and 0.80 at the flow gauge for maximum and total event flows respectively.

It should be noted that most of the largest events in the available data sets were used during the calibration phase to ensure model accuracy over as large of a range as possible. The validation events therefore tended to be smaller than the calibration events and often lacked data from one of the three rain gauges. Nonetheless, the validation process served to increase confidence that the model is able to sufficiently simulate real events.

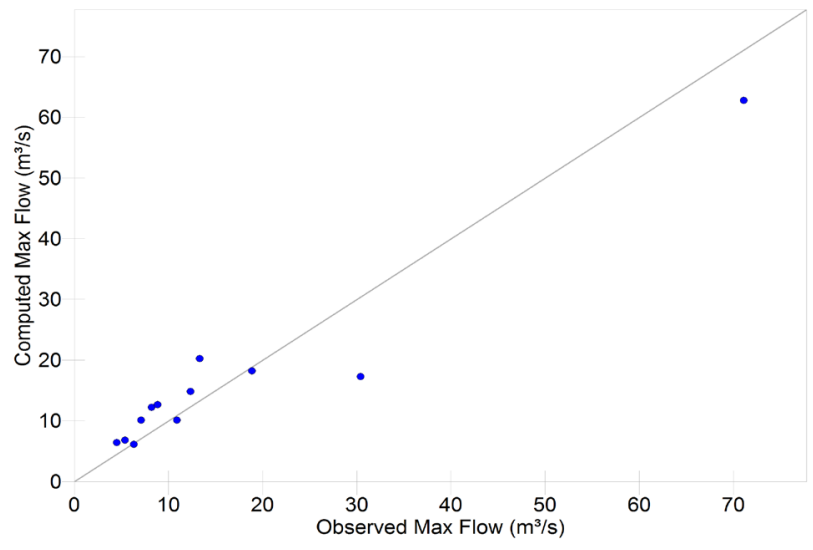

Figure 9 Computed and observed maximum flows of validation events at $02 \mathrm{HB} 030$ flow gauge

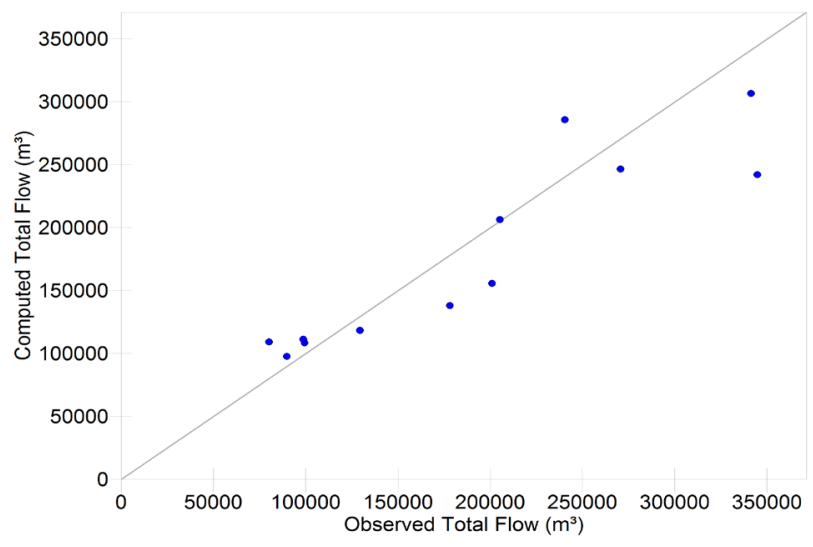

Figure 10 Computed and observed total flows of validation events at $02 \mathrm{HB} 030$ flow gauge.

\section{Model Uses and Future Work}

The dual drainage model is currently being used to evaluate the performance of the Cooksville Creek watershed's minor and major drainage systems under various design and recent major events, including $4 \mathrm{~h}$ Chicago storms ( 2 y, 5 y, 10 y, 25 y, 50 y and
$100 \mathrm{y}$ return periods) and the 2009-08-04 and 2013-07-08 events. The areas where the capacity of the minor and major drainage systems should be further investigated will be identified based on the hydraulic grade line results of the $10 \mathrm{y}$ and $100 \mathrm{y}$ simulations respectively.

Moving forward, the model will be used to evaluate various what if? scenarios (e.g. climate change, pipe and inlet blockages, development pressures) as well as to test the impact of proposed infrastructure upgrades and alterations (e.g. new pipes, downspout disconnections, additional storage, green stormwater infrastructure).

Considering recent problems with basement flooding experienced in the watershed, the next phase of this study will involve the addition of a sanitary sewer system component for detailed neighbourhood scale submodels. Detailed modeling at a neighbourhood scale will reduce uncertainty in those areas and help to identify specific flooding causes. The submodels will have their input parameters recalibrated based on data from flow gauges installed in storm and sanitary sewers. When the initial model calibration was performed there were not yet flow gauges installed in any sewers so the accuracy of computed flows within individual pipes is not yet known.

\section{Conclusions}

Dual drainage modeling methods have improved greatly over the past decades and should be employed when simulating situations where street flooding may occur and interactions between the minor and major systems are significant. Present day computational power and modeling packages allow for the streamlined development and calibration of complex citywide dual drainage models incorporating thousands of drainage areas and minor and major drainage elements.

This paper has outlined the development and calibration of the Cooksville Creek dual drainage SWMM5 model. In simulations of regional events and design events larger than $10 \mathrm{y}$ flow occurred in many of the major system conduits, demonstrating the need of the dual drainage component for accurate representation of the system. The model's calibration and validation results indicated a very good agreement between computed and observed maximum and total flows for 12 calibration events and 12 validation events. While assigning representative initial model parameter values is important, calibration of the model to a variety of observed events is also required to ensure the best possible model accuracy.

The developed dual drainage model is currently used as a decision support tool to help evaluate various drainage scenarios and prioritize potential stormwater infrastructure upgrades in the Cooksville Creek watershed. As additional data becomes available in the future the model will be updated and recalibrated. 


\section{References}

ASCE (American Society of Civil Engineers). 1992. Design \& Construction of Urban Stormwater Management Systems: Manual of Practice No. 77. New York: American Society of Civil Engineers.

City of Toronto, 2010. “Toronto Area 3 Drainage Study Modeling Technical Memorandum. Standard Inlet Capture CurveAppendix 2.3.2." Toronto: City of Toronto. http://www1.toronto.ca/city_of_toronto/policy_planning_ finance_administration/public_consultation_unit/toronto_water/basement_flooding/files/pdf/5.pdf.

Denver Regional Council of Governments. 1969. Urban Storm Drainage Criteria Manual, 3 vols. Denver, CO: Wright-McLaughlin Engineers.

Djordjević, S., M. Ivetic, C. Maksimović and A. Rajcevic. 1991. "An approach to the simulation of street flooding in the modeling of surcharged flow in storm sewers." Proceedings: New Technologies in Urban Drainage UDT 91:101-8.

Djordjević, S., D. Prodanović and Č. Maksimović. 1999. "An approach to simulation of dual drainage." Water Science and Technology 39 (9): 95-103.

Environment Canada. 2013. Water Survey of Canada-Archived Hydrometric Data. Fredericton, New Brunswick: Environment Canada. https://wateroffice.ec.gc.ca.

James W., L. Rossman and W. R. C. James. 2010. User's Guide to SWMM, 13th ed. Guelph: CHI Press. http://www.chiwater.com/Files/UsersGuideToSWMM5Edn13.pdf.

James, R. W., K. Finney and W. James. 2012. “Auto-Integrating Multiple HEC-RAS Flood-Lie Models into Catchment-Wide SWMM Flood Forecasting Models." AWRA Hydrology \& Watershed Management Technical Committee 7:1-15.
Leandro, J., A. S. Chen, S. Djordjević and D. A. Savić. 2009. “Comparison of 1D/1D and 1D/2D Coupled (Sewer/Surface) Hydraulic Models for Urban Flood Simulation." Journal of Hydraulic Engineering 135 (6): 495-504.

Mark, O., S. Weesakul, C. Apirumanekul, S. B. Aroonnet and S. Djordjević. 2004. "Potential and Limitations of 1D Modeling of Urban Flooding." Journal of Hydrology 299 (3): 284-99.

McCuen, R. H., P. A. Johnson and R. M. Ragan. 1996. Highway Hydrology. Washington, DC: Federal Highway Administration. FHWA-SA-96-067.

Moriasi, D. N., J. G. Arnold, M. W. Van Liew, R. L. Bingner, R. D. Harmel and T. L Veith. 2007. “Model Evaluation Guidelines for Systematic Quantification of Accuracy in Watershed Simulations." Transactions of the ASABE 50 (3): 885-900.

Rawls, W. J., D. L Brakensiek and N. Miller. 1983. "Green-Ampt Infiltration Parameters from Soils Data." Journal of Hydraulic Engineering 109 (1): 62-70.

Rossman, L. A. 2015. Storm Water Management Model User's Manual Version 5.1. Washington, DC: United States Environmental Protection Agency. http://www2.epa.gov/water-research/storm-watermanagement-model-swmm.

Smith, M. B. 2006. “Comment on 'Analysis and Modeling of Flooding in Urban Drainage Systems"'. Journal of Hydrology 317 (3): 355-63.

Wisner, P. E. and A. M. Kassem. 1982. “Analysis of Dual Drainage Systems by OTTSWMM." In Urban Drainage Systems: Proceedings of the First International Seminar, 93-108. Southampton, England: Computational Mechanics Centre. 